\title{
Association of Plasma Low-Density Lipoprotein Receptor-Related Protein-1 (LRP1) with Undernutrition: A Case-Control Study in Bangladeshi Adults
}

\section{Md. Mehedi Hasan}

International Centre for Diarrhoeal Disease Research Bangladesh

Shah Mohammad Fahim

International Centre for Diarrhoeal Disease Research Bangladesh

Subhasish Das ( $\square$ subhasish.das@icddrb.org )

International Centre for Diarrhoeal Disease Research Bangladesh

Md. Amran Gazi

International Centre for Diarrhoeal Disease Research Bangladesh

Mustafa Mahfuz

International Centre for Diarrhoeal Disease Research Bangladesh

Tahmeed Ahmed

International Centre for Diarrhoeal Disease Research Bangladesh

\section{Research}

Keywords: LRP1, Undernutrition, Adults, Bangladesh

Posted Date: August 12th, 2020

DOI: https://doi.org/10.21203/rs.3.rs-56409/v1

License: (c) (i) This work is licensed under a Creative Commons Attribution 4.0 International License.

Read Full License 


\section{Abstract}

Background: Studies revealed that LRP1 plays pivotal role in adipogenesis, whereas silencing of LRP1 expression can cause inhibition of adipogenesis in animal model and contribute to reduced body size. Therefore a reduction in the level of adipocytic LRP1 might have a role on weight loss. But there is no study that has explored the role of LRP1 on weight loss of human adults. However, it is not feasible to examine the role of adipocytic LRP1 on weight loss due to invasive collection procedure of adipose tissue. But plasma LRP1 can fill that void as it is a biomarker of adipocytic LRP1. Therefore, the aim of this study was to investigate the relationship of plasma low-density lipoprotein receptor-related protein-1 (LRP1) with undernutrition.

Methods: A total of 270 Bangladeshi slum-dwelling adults ( 135 cases, $\mathrm{BMI}<18.5 \mathrm{~kg} / \mathrm{m}^{2}$ and 135 controls, BMI $18.5-24.9 \mathrm{~kg} / \mathrm{m}^{2}$ ) were enrolled. Their socio-economic, demographic, anthropometric and biomedical data were collected. Plasma LRP1, C-reactive protein (CRP), alpha-1 acid glycoprotein (AGP), and ferritin levels were measured by ELISA, hemoglobin by Hemocue and zinc by atomic absorption spectrometry.

Results: The median (IQR) values of plasma LRP1, CRP, AGP, Hemoglobin, zinc and ferritin were 1673.1 (1382.5- 1886.2) ng/ml, $2.1(0.9$ - 4.4) mg/L, 75.8 (62.9 - 95.9) mg/dL, $13.2(12-14.3) \mathrm{g} / \mathrm{dL}, 0.74(0.7$ - 0.8) $\mathrm{mg} / \mathrm{L}, 59.9(26.4-123.2) \mathrm{ng} / \mathrm{mL}$ in healthy participants and $707.7(588.6-839.9) \mathrm{ng} / \mathrm{ml}, 0.8(0.2-$ 1.7) $\mathrm{mg} / \mathrm{L}, 64.7(52.9-86.9) \mathrm{mg} / \mathrm{dL}, 12.4(11.4-13.4) \mathrm{g} / \mathrm{dL}, 0.71(0.6-0.8) \mathrm{mg} / \mathrm{mL}, 43.7(19.9-80.2)$ $\mathrm{ng} / \mathrm{mL}$ in undernourished participants, respectively. A strong positive correlation $(r=0.70, \mathrm{p}<0.05)$ between LRP1 and body mass index (BMI) was found. Multivariable logistic regression analysis revealed a positive association between low plasma LRP1 (Adj. OR=0.98, $\mathrm{Cl}=0.98,0.99$ and $p<0.05$ ) and undernutrition.

Conclusions: The study found that increased level of LRP1 is associated with increased BMI, whereas lower level can contribute to low BMI.

\section{Background}

Malnutrition is a public health concern over the world, particularly in developing countries [1]. It is an imbalanced nutritional condition that includes both under- and over-nutrition. The adults having body mass index $(\mathrm{BMI})<18.5 \mathrm{~kg} / \mathrm{m}^{2}$ are referred to be undernourished, while over-nutrition includes overweight and obesity [2, 3]. It has been estimated that undernutrition is on the rise and reached 821 million people in 2017 around the world, whereas in Southern Asia the prevalence of undernutrition is 14.8\% [4]. In Bangladesh, the scenario is even worse; nearly $30 \%$ of the adult population including both female and male were undernourished in 2011 [5]. This figure got reduced to 16\% for adult women in 2015 [6]. Undernutrition affects adulthood by reducing performance capacity and low productivity of work as well as leading to complicated pregnancy outcome and poor health conditions $[5,7,8]$. Several factors such as inadequate dietary intake, swallowing issues, eating/chewing problem, dysphagia, depressive 
symptoms and older age are associated with weight loss and low BMI and can cause undernutrition among adults [9]. Overall, environmental, genetic and epigenetic changes may cause undernutrition in children [10-12], but there is a paucity of evidence to support a causal relation of these factors with undernutrition in adults.

LRP1(low-density lipoprotein receptor-related protein-1) is an endocytic receptor that plays important role in binding and internalization of a wide range of biological ligands [13]. It functions in various cellular activities including proliferation, migration and differentiation of cell as well as activation of lysosomal enzymes $[13,14]$. It has a potential role in phagocytosis, which is necessary for removal of infectious agents [13], thus improves health condition through elimination of infection. Moreover, it also plays a pivotal role in adipogenesis and lipid metabolism in mature adipocytes. A previous study indicates that expression of LRP1 is up regulated in adipose tissue of obese human and mouse [15]. The study also showed that silencing of LRP1 expression in mouse inhibits adipogenesis through inhibition of nuclear peroxisome proliferator-activated receptor $\gamma$, which is vital for the initiation of adipogenesis [15]. Another study also demonstrated that reduced expression of LRP1 could contribute to stunted phenotype in children [10]. The study also reported that reduced body size, loss of intestinal barrier function as well as gut inflammation have been observed in LRP1 knockout mice [10]. In addition, it has been elicited that LRP1 (in adipocyte) knockout mice has small amount of fat and lipid depleted adipocytes which caused reduced body weight [16-18]. Therefore, a reduction in the level of adipocytic LRP1 might have a role on weight loss. Genetic analysis revealed contradictory results about the relationship between BMI and LRP1 gene. LRP1 genotype has a strong influence on BMI and waist circumference [19], while another study found no association between certain SNP (single nucleotide polymorphism) of LRP1 gene and BMI [20]. But there is no study that has explored the role of LRP1 on weight loss of human adults. However, it is not feasible to examine the role of adipocytic LRP1 on weight loss due to invasive collection procedure (abdominal lipectomy) of adipose tissue. But plasma LRP1 can fill that void as it is a biomarker of adipocytic LRP1 and plasma LRP1 also represent the volume of adipose tissue [21]. In this study, we aimed to investigate the relationship of plasma LRP1 with undernutrition in Bangladeshi adults who lives in slums.

\section{Methods}

\section{Study design, participants and study site}

A group of 270 Bangladeshi adults were recruited in a case-control manner from our ongoing "Bangladesh Environmental Enteric Dysfunction (BEED)" study. The detailed study protocol has been published elsewhere [22]. The case group was comprised of 135 undernourished participants $(\mathrm{BMI}<$ $18.5 \mathrm{~kg} / \mathrm{m}^{2}$ ). A total of 135 healthy participants (BMI from $18.5 \mathrm{~kg} / \mathrm{m}^{2}$ to $24.9 \mathrm{~kg} / \mathrm{m}^{2}$ ) without any history of chronic diseases were enrolled as controls. Study participants were recruited from Bauniabadh area of Mirpur, Dhaka, Bangladesh.

\section{Ethical consideration}


The study protocol was approved by the institutional review board of the International Centre for Diarrhoeal Disease Research, Bangladesh (icddr,b). All participants were informed about the study and written consents were obtained from them.

\section{Data collection, sample collection and laboratory analyses}

Anthropometric, socio-economic and demographic data were collected from each of the study participants by trained field staff. $2 \mathrm{ml}$ of venous blood was collected in a blood collection tube (SMonovette $7.5 \mathrm{~mL}$, Sarstedt) by phlebotomist after maintaining all the aseptic conditions and transported to laboratory under cold-chain maintenance. Plasma was collected by centrifugation at 4000 rpm for 10 minutes and preserved at $-80^{\circ} \mathrm{C}$ prior to biomarker analysis. Plasma biomarker including LRP1, CRP, AGP, and ferritin were measured using commercially available ELISA kits. Zinc was measured in plasma by atomic absorption spectrometry technique and HemoCue Hb 201 System was used to measure hemoglobin. All the laboratory work was done at the parasitology laboratory of icddr,b.

\section{Statistical analyses}

Exploratory data analyses were performed to describe the characteristics of the enrolled participants using Mann-Whitney $U$ test and Chi-square test. The variables following skewed distributions were presented as median with inter-quartile ranges, whereas categorical variables were presented as frequencies with percentages. Mann-Whitney $U$ test was used to detect the differences in the age, BMI as well as plasma biomarker including LRP1, CRP, AGP, hemoglobin, zinc and ferritin, while Chi-square test were used for comparing categorical variables (sex, smoking status and substance abuse) of the undernourished and healthy participants. Spearman's correlation coefficients $(r)$ were calculated to assess the correlation of the level of plasma LRP1 with BMI, levels of hemoglobin, zinc, ferritin and inflammatory markers (CRP and AGP). A multivariable logistic regression analysis was performed to measure the association between plasma LRP1 level and undernutrition, where presence $(\mathrm{BMI}<$ $18.5 \mathrm{~kg} / \mathrm{m}^{2}$ ) or absence (BMI from $18.5 \mathrm{~kg} / \mathrm{m}^{2}$ to $24.9 \mathrm{~kg} / \mathrm{m}^{2}$ ) of undernutrition was the outcome variable and level of plasma LRP1 was the explanatory variable. In this study age, sex, smoking status and Hemoglobin were considered as cofounding variables on the basis of literature review (20) and variables including CRP, AGP, zinc, ferritin with $p$ value $<0.05$ in bivariate analysis were also included as confounding variables. In all the analyses, p-value less than < 0.05 was considered statistically significant. All the analyses were done using STATA version - 13.

\section{Results}

\section{Descriptive information of the study participants}

Table 1 presents the descriptive statistics of the participants. Among the participants nearly one-third was male. The median (IQR) ages of the healthy and undernourished participants were 24 (19-30) years and 21 (19-26) years, respectively. And the median (IQR) BMI of the healthy and undernourished participants were $21.8(20.2-23.5) \mathrm{Kg} / \mathrm{m}^{2}$ and $17.4(16.8-18) \mathrm{Kg} / \mathrm{m}^{2}$, respectively. Approximately $14 \%$ healthy and 
$5 \%$ undernourished participants were smokers and smoking status significantly $(p<0.05)$ differ between these two study groups. Almost similar numbers of healthy and undernourished participants were addicted with different types of substances such as betel leaf, areca nut, slaked lime.

Table-1: Descriptive characteristics of the study participants

\begin{tabular}{|c|c|c|c|}
\hline Variables & $\begin{array}{l}\text { Healthy } \\
(n=135)\end{array}$ & $\begin{array}{l}\text { Undernourished } \\
(n=135)\end{array}$ & p-value \\
\hline \multicolumn{4}{|l|}{ n (\%) } \\
\hline Sex (Male) & $40(29.6)$ & $25(18.5)$ & $<0.05^{\star}$ \\
\hline Smoking status (Yes) & $18(13.3)$ & $6(4.4)$ & $<0.05^{\star}$ \\
\hline Substances abuse (Yes) & $9(6.6)$ & $9(6.6)$ & $0.9 *$ \\
\hline \multicolumn{4}{|l|}{ Median (IQR) } \\
\hline Age (Years) & $24(19-30)$ & $21(19-26)$ & $<0.05^{\star \star}$ \\
\hline $\operatorname{BMI}\left(\mathrm{Kg} / \mathrm{m}^{2}\right)$ & $21.8(20.2-23.5)$ & $17.4(16.8-18)$ & $<0.05^{\star \star}$ \\
\hline $\mathrm{CRP}(\mathrm{mg} / \mathrm{L})$ & $2.1(0.9-4.4)$ & $0.8(0.2-1.7)$ & $<0.05^{\star \star}$ \\
\hline AGP $(\mathrm{mg} / \mathrm{dL})$ & $75.8(62.9-95.9)$ & $64.7(52.9-86.9)$ & $<0.05^{\star \star}$ \\
\hline Hemoglobin (g/dL) & $13.2(12-14.3)$ & $12.4(11.4-13.4)$ & $<0.05^{\star \star}$ \\
\hline $\operatorname{Zinc}(\mathrm{mg} / \mathrm{L})$ & $0.74(0.7-0.8)$ & $0.71(0.6-0.8)$ & $<0.05^{\star \star}$ \\
\hline Ferritin (ng/mL) & $59.9(26.4-123.2)$ & $43.7(19.9-80.2)$ & $<0.05^{\star \star}$ \\
\hline \multicolumn{4}{|c|}{$\begin{array}{l}\text { *Chi-square test were used for comparing categorical variables (sex, smoking status and substance } \\
\text { abuse) }\end{array}$} \\
\hline
\end{tabular}

\section{Plasma biomarker levels in the study participants}

The levels of CRP, AGP, hemoglobin, zinc and ferritin were significantly $(p<0.05)$ higher in healthy participants compared to undernourished participants (showed in table-1). The median (IQR) value of CRP, AGP, hemoglobin, zinc and ferritin were $2.1(0.9-4.4) \mathrm{mg} / \mathrm{L}, 75.8$ (62.9-95.9) mg/dL, 13.2 (12-14.3) $\mathrm{g} / \mathrm{dL}, 0.74(0.7-0.8) \mathrm{mg} / \mathrm{L}, 59.9(26.4-123.2) \mathrm{ng} / \mathrm{mL}$ in healthy participants and $0.8(0.2-1.7) \mathrm{mg} / \mathrm{L}, 64.7$ (52.9-86.9) mg/dL, $12.4(11.4-13.4) \mathrm{g} / \mathrm{dL}, 0.71(0.6-0.8) \mathrm{mg} / \mathrm{mL}, 43.7(19.9-80.2) \mathrm{ng} / \mathrm{mL}$ in undernourished participants, respectively.

\section{Correlation among biochemical parameters and anthropometric measurements}


There was a strong positive $(r=0.7)$ correlation between LRP1 and BMI and this finding was statistically significant $(p<0.05)$. Similarly, positive correlation was found for CRP, AGP, Hb, ferritin and zinc with LRP1 and BMI. Correlations among different variables are presented in table-2.

Table-2: Spearman's correlation of LRP1 with BMI and different biomarkers both in healthy and undernourished participants

\begin{tabular}{|llllllll|}
\hline Variables & BMI & LRP1 & CRP & AGP & Hemoglobin & Ferritin & Zinc \\
\hline BMI & 1.00 & & & & & & \\
\hline LRP1 & $0.70^{\star}$ & 1.00 & & & & & \\
\hline CRP & $0.35^{\star}$ & $0.25^{\star}$ & 1.00 & & & & \\
\hline AGP & $0.17^{*}$ & $0.20^{\star}$ & $0.36^{\star}$ & 1.00 & & & \\
\hline Hemoglobin & $0.18^{\star}$ & $0.25^{\star}$ & -0.06 & -0.11 & 1.00 & & \\
\hline Ferritin & 0.07 & $0.18^{*}$ & 0.07 & 0.01 & $0.36^{*}$ & 1.00 & \\
\hline Zinc & $0.11^{*}$ & $0.17^{*}$ & 0.01 & -0.007 & $0.30^{*}$ & $0.20 *$ & 1.00 \\
\hline *p-value $<0.05$ & & & & & & & \\
\hline
\end{tabular}

\section{The association between plasma LRP1 and undernutrition}

Comparison of plasma LRP1 level between undernourished and healthy participants revealed that plasma LRP1 level was significantly $(p<0.05)$ lower in undernourished participants compare to healthy participants (presented in Fig. 1). The median (IQR) values of plasma LRP1 in undernourished and healthy participants were $707.7(588.6-839.9) \mathrm{ng} / \mathrm{ml}$ and 1673.1 (1382.5-1886.2) $\mathrm{ng} / \mathrm{ml}$ respectively. Multivariable logistic regression analysis showed that lower level of plasma LRP1 (Adj.OR $=0.98, \mathrm{Cl}=$ $0.98,0.99$ and $p$-value $<0.05)$ was positively associated with undernutrition. In bivariate analysis, age, sex, LRP1, CRP, AGP, Hemoglobin, Zinc, Ferritin and smoking status were found to be associated with adult undernutrition. But, only LRP1, CRP and smoking status were found to be associated with undernutrition upon adjustment for age, sex, substance abuse, AGP, Hemoglobin, Ferritin and Zinc in multivariable analysis, where, lower level of LRP1 and CRP were positively associated with undernutrition. And the findings were significant in case of both bivariate and multivariate analysis. The results of logistic regression analysis are presented in table-3.

Table-3: Multivariable logistic regression analysis to explore the association between plasma LRP1 and undernutrition 


\begin{tabular}{|lllllll|}
\hline Variables & OR & $95 \% \mathrm{Cl}$ & p-value & Adj. OR & $95 \% \mathrm{Cl}$ & p-value \\
\hline Age & 0.96 & $0.92,0.99$ & $<0.05$ & 1.01 & $0.91,1.11$ & 0.81 \\
Sex & 1.85 & $1.04,3.27$ & $<0.05$ & 0.56 & $0.06,5.09$ & 0.61 \\
LRP1 & 0.99 & $0.99,1.00$ & $<0.05$ & 0.98 & $0.98,0.99$ & $<0.05$ \\
CRP & 0.87 & $0.80,0.94$ & $<0.05$ & 0.71 & $0.58,0.87$ & $<0.05$ \\
AGP & 0.98 & $0.97,0.99$ & $<0.05$ & 1.01 & $0.99,1.03$ & 0.25 \\
\hline Hemoglobin & 0.75 & $0.65,0.87$ & $<0.05$ & 0.65 & $0.42,1.04$ & 0.07 \\
\hline Ferritin & 0.99 & $0.99,1.00$ & $<0.05$ & 1.00 & $0.99,1.01$ & 0.47 \\
\hline Zinc & 0.07 & $0.01,0.63$ & $<0.05$ & 59.33 & $0.13,27072.14$ & 0.19 \\
\hline Smoking status & 0.30 & $0.11,0.78$ & $<0.05$ & 0.05 & $0.003,0.763$ & $<0.05$ \\
\hline Substance abuse & 0.99 & $0.38,2.58$ & 0.98 & & & \\
\hline OR: Odds ratio; Cl: Confidence Interval; Adj. OR: Adjusted OR & & \\
\hline
\end{tabular}

\section{Discussion}

In the present study, significant positive association was found between lower level of plasma LRP1 and undernutrition in Bangladeshi adults. Overall, our study results revealed that plasma LRP1 level was significantly lower in undernourished participants compared to their corresponding healthy control. Such lower level of plasma LRP1 might be a consequence of reduced expression of LRP1 in adipocytes [21]. This finding is supported by the study conducted by Uchiyama R. et al. [10], where they reported that reduced expression of LRP1 can contribute to stunted phenotype in children. Both the stunted children and undernourished adults are alluded to suffer from undernutrition. From the nutritional point of view it can be inferred that both stunted and undernourished condition might be a result of reduced expression of LRP1. In addition, spearman's correlation between plasma LRP1 and BMI also demonstrated a strong positive correlation between these two variables. This finding suggests that increased level of LRP1 is responsible for increased BMI while a decreased level causes low BMI. On the other hand, genetic analysis published conflicting findings such as BMI and waist circumference were strongly influenced by LRP1 genotype, while another study found no association between BMI and some SNP of LRP1 gene in human $[19,20]$. Moreover, multivariable logistic regression analysis suggests that higher level of LRP1 plays protective role against undernutrition in Bangladeshi adults. A study conducted in undernourished participants found an association between CRP and undernutrition [23], which is also in accordance with our finding. Another study found that plasma CRP level was lower in undernourished participants [24], which is consistent with our finding. Moreover, CRP level was positively correlated with BMI in our analysis which is also supported by another study [25]. 
Various aspects such as environmental and genetic factors as well as epigenetic changes may cause undernutrition in adults and children [8-11]. LRP1 is an endocytic receptor, crucial for the initiation of adipogenesis through activation of nuclear peroxisome proliferator-activated receptor $\gamma$, responsible for weight gain. On the other hand, silencing of LRP1 expression can cause inhibition of adipogenesis in mouse model, causing reduced body weight [15]. Studies showed that, dietary lipids in chylomicron remnants enter into hepatocytes by the action of LRP1 through binding to Apolipoprotein E (ApoE), lipoprotein lipase (LpL) and hepatic lipase [26-29]. It has been reported that ApoE is crucial for triglycerides accumulation in adipocytes and found to have a pivotal role in adipocytes differentiation and obesity [30-32]. There is strong evidence that LRP1 plays important role in some signal transduction pathways that are crucial for cell proliferation and cell migration. In addition, LRP1 also mediates trafficking and storage of lipid in adipocytes [33]. Another study also revealed that impairment of TGRL (Triglyceride rich lipoprotein) assimilation in adipose tissue is accompanied by the absence of LRP1, resulting in reduced fat mass [34]. Altogether, these findings strongly suggest that lower level of LRP1 may have an effect on adipocytes differentiation and can contribute to undernutrition.

In our study, we only measured the plasma LRP1 level but we did not measure the expression level of adipocytic LRP1 in undernourished participants due to invasive collection procedure of adipose tissue. In addition, we did not investigate the effect of inhibition of LRP1 expression in case of human to explore whether reduced expression may or may not contribute to undernutrition due to ethical consideration. These are the limitations of this study. However, this was the first study that explored the relationship between plasma LRP1 level and undernutrition in human adults, which is the strength of this study. This study also reported about the correlation between plasma LRP1 and BMI of adults at the first time.

\section{Conclusions}

Our results suggest that increased level of LRP1 is associated with increased BMI, whereas lower level can contribute to low BMI in adults. This result suggests the importance of investigating the association between plasma LRP1 and undernutrition in children.

\section{Abbreviations}

LRP1: Low-density lipoprotein receptor-related protein-1; CRP: C-reactive protein; AGP: alpha-1 acid glycoprotein; BMl: Body mass index; SNP: single nucleotide polymorphism; BEED: Bangladesh Environmental Enteric Dysfunction; ApoE: Apolipoprotein E; LpL: Lipoprotein lipase; TGRL: Triglyceride rich lipoprotein.

\section{Declarations}

\section{Acknowledgments}


The authors would like to thank all the participants and their parents for sharing their time and providing consent and information necessary for the successful completion of the study. The authors also acknowledge the contribution of icddr,b's core donors including Governments of the People's Republic of Bangladesh, Canada, Sweden and UK for their continuous support and commitment to the icddr,b's research efforts.

\section{Funding}

BEED study was funded by the Bill and Melinda Gates Foundation under its Global Health Program and the BMGF Project investment id is OPP1136751.

\section{Availability of data and materials}

The data set that was created during the study is not publicly available due to the restriction of funder. However, suggestion for data analysis can be made to corresponding author.

\section{Authors' contributions}

TA conceptualized the study. MMH and SMF wrote the manuscript and analyzed the data. SMF also designed the study and supervised the data collection. MMH and MAG did the laboratory analysis. SD critically reviewed the manuscript and developed the final version. MM, SMF involved in the development of study protocol. All authors commented on manuscript and approved the final version.

\section{Ethics Approval and consent of participants}

The study protocol was approved by Institutional review board of the International Centre for Diarrhoeal Disease Research, Bangladesh (icddr,b). Protocol number-PR-16007. Written consent was collected from all the participants during enrollment.

\section{Consent of publication}

Not applicable

\section{Competing interests}

The authors declared no competing interests.

\section{References}


1. Müller O, Krawinkel M. Malnutrition and health in developing countries. Cmaj. 2005;173(3):279-86.

2. Bharati S, Pal M, Sen S, Bharati P. Malnutrition and anaemia among adult women in India. J Biosoc Sci. 2019:1-11.

3. www.who.int/features/qa/malnutrition/en/ WHO.

4. Food and Agriculture Organization of the United Nations. Food Security and Nutrition around the world. Rome: The Organization 2018.

5. Biswas T, Garnett SP, Pervin S, Rawal LB. The prevalence of underweight, overweight and obesity in Bangladeshi adults: Data from a national survey. PloS one. 2017;12(5):e0177395.

6. State of food security and nutrition in Bangladesh 2015 . (2016). Accessed: August 29 hsbabirFsofs.

7. Nube M, Van Den Boom G. Gender and adult undernutrition in developing countries. Ann Hum Biol. 2003;30(5):520-37.

8. Benson T, Shekar M. Trends and issues in child undernutrition. Disease and Mortality in SubSaharan Africa 2nd edition: The International Bank for Reconstruction and Development/The World Bank. 2006.

9. Tamura BK, Bell CL, Masaki KH, Amella EJ. Factors associated with weight loss, low BMI, and malnutrition among nursing home patients: a systematic review of the literature. J Am Med Dir Assoc. 2013;14(9):649-55.

10. Uchiyama R, Kupkova K, Shetty SJ, Linford AS, Pray-Grant MG, Wagar LE, et al. Histone H3 lysine 4 methylation signature associated with human undernutrition. Proc Natl Acad Sci U S A. 2018;115(48):E11264-E73.

11. Ahmed T, Haque R, Shamsir Ahmed AM, Petri Jr WA, Cravioto A. Use of metagenomics to understand the genetic basis of malnutrition. Nutr Rev. 2009;67(suppl_2):S201-S6.

12. Schmidt CW. Beyond malnutrition: the role of sanitation in stunted growth. NLM-Export; 2014.

13. Lillis AP, Van Duyn LB, Murphy-Ullrich JE, Strickland DK. LDL receptor-related protein 1: unique tissuespecific functions revealed by selective gene knockout studies. Physiol. Rev. 2008;88(3):887-918.

14. Safina D, Schlitt F, Romeo R, Pflanzner T, Pietrzik CU, Narayanaswami V, et al. Low-density lipoprotein receptor-related protein 1 is a novel modulator of radial glia stem cell proliferation, survival, and differentiation. Glia. 2016;64(8):1363-80.

15. Masson O, Chavey C, Dray C, Meulle A, Daviaud D, Quilliot D, et al. LRP1 receptor controls adipogenesis and is up-regulated in human and mouse obese adipose tissue. PloS one. 2009;4(10):e7422.

16. Chappell D, Fry G, Waknitz M, Muhonen L, Pladet M, Iverius P, et al. Lipoprotein lipase induces catabolism of normal triglyceride-rich lipoproteins via the low density lipoprotein receptor- related protein/alpha 2-macroglobulin receptor in vitro. A process facilitated by cell-surface proteoglycans. $J$ Biol Chem. 1993;268(19):14168-75.

17. Chappell DA, Inoue I, Fry GL, Pladet MW, Bowen SL, Iverius P-H, et al. Cellular catabolism of normal very low density lipoproteins via the low density lipoprotein receptor-related protein/alpha 2- 
macroglobulin receptor is induced by the C-terminal domain of lipoprotein lipase. J Biol Chem. 1994;269(27):18001-6.

18. Nykjaer A, Bengtsson-Olivecrona G, Lookene A, Moestrup S, Petersen C, Weber W, et al. The alpha 2macroglobulin receptor/low density lipoprotein receptor-related protein binds lipoprotein lipase and beta-migrating very low density lipoprotein associated with the lipase. J Biol Chem. 1993;268(20):15048-55.

19. Vučinić N, Stokić E, Djan I, Obreht D, Veličković N, Stankov K, et al. The LRP1 gene polymorphism is associated with increased risk of metabolic syndrome prevalence in the Serbian population. Balkan Journal of Medical Genetics. 2017;20(1):51-8.

20. Frazier-Wood AC, Kabagambe EK, Borecki IB, Tiwari HK, Ordovas JM, Arnett DK. Preliminary evidence for an association between LRP-1 genotype and body mass index in humans. PLoS one. 2012;7(2):e30732.

21. de Gonzalo-Calvo D, Colom C, Vilades D, Rivas-Urbina A, Moustafa A-H, Pérez-Cuellar M, et al. Soluble LRP1 is an independent biomarker of epicardial fat volume in patients with type 1 diabetes mellitus. Sci Rep. 2018;8(1):1054.

22. Mahfuz M, Das S, Mazumder RN, Rahman MM, Haque R, Bhuiyan MMR, et al. Bangladesh Environmental Enteric Dysfunction (BEED) study: protocol for a community-based intervention study to validate non-invasive biomarkers of environmental enteric dysfunction. BMJ open. 2017;7(8):e017768.

23. Coutinho HM, Leenstra T, Acosta LP, Su L, Jarilla B, Jiz MA, et al. Pro-inflammatory cytokines and Creactive protein are associated with undernutrition in the context of Schistosoma japonicum infection. Am J Trop Med Hyg. 2006;75(4):720-6.

24. Loprinzi PD, Crespo CJ, Andersen RE, Smit E. Association of body mass index with cardiovascular disease biomarkers. Am J Prev Med. 2015;48(3):338-44.

25. Kao T-W, Lu I-S, Liao K-C, Lai H-Y, Loh C-H, Kuo H-K. Associations between body mass index and serum levels of C-reactive protein. S Afr Med J. 2009;99(5).

26. Beisiegel U, Weber W, Ihrke G, Herz J, Stanley KK. The LDL-receptor-related protein, LRP, is an apolipoprotein E-binding protein. Nature. 1989;341(6238):162.

27. Kowal RC, Herz J, Goldstein JL, Esser V, Brown MS. Low density lipoprotein receptor-related protein mediates uptake of cholesteryl esters derived from apoprotein E-enriched lipoproteins. Proc Natl Acad Sci U S A. 1989;86(15):5810-4.

28. Beisiegel U, Weber W, Bengtsson-Olivecrona G. Lipoprotein lipase enhances the binding of chylomicrons to low density lipoprotein receptor-related protein. Proc Natl Acad Sci U S A. 1991;88(19):8342-6.

29. Kounnas MZ, Chappell DA, Wong H, Argraves WS, Strickland DK. The cellular internalization and degradation of hepatic lipase is mediated by low density lipoprotein receptor-related protein and requires cell surface proteoglycans. J Biol Chem.1995;270(16):9307-12. 
30. Huang ZH, Reardon CA, Mazzone T. Endogenous ApoE expression modulates adipocyte triglyceride content and turnover. Diabetes. 2006;55(12):3394-402.

31. Yue L, Rasouli N, Ranganathan G, Kern PA, Mazzone T. Divergent effects of peroxisome proliferatoractivated receptor $y$ agonists and tumor necrosis factor $\mathrm{a}$ on adipocyte ApoE expression. J Biol Chem. 2004;279(46):47626-32.

32. Gao J, Katagiri H, Ishigaki Y, Yamada T, Ogihara T, Imai J, et al. Involvement of apolipoprotein E in excess fat accumulation and insulin resistance. Diabetes. 2007;56(1):24-33.

33. Terrand J, Bruban V, Zhou L, Gong W, El Asmar Z, May P, et al. LRP1 controls intracellular cholesterol storage and fatty acid synthesis through modulation of Wnt signaling. J Biol Chem. 2009;284(1):381-8.

34. Hofmann SM, Zhou L, Perez-Tilve D, Greer T, Grant E, Wancata L, et al. Adipocyte LDL receptorrelated protein-1 expression modulates postprandial lipid transport and glucose homeostasis in mice. J Clin Inves. 2007;117(11):3271-82.

\section{Figures}

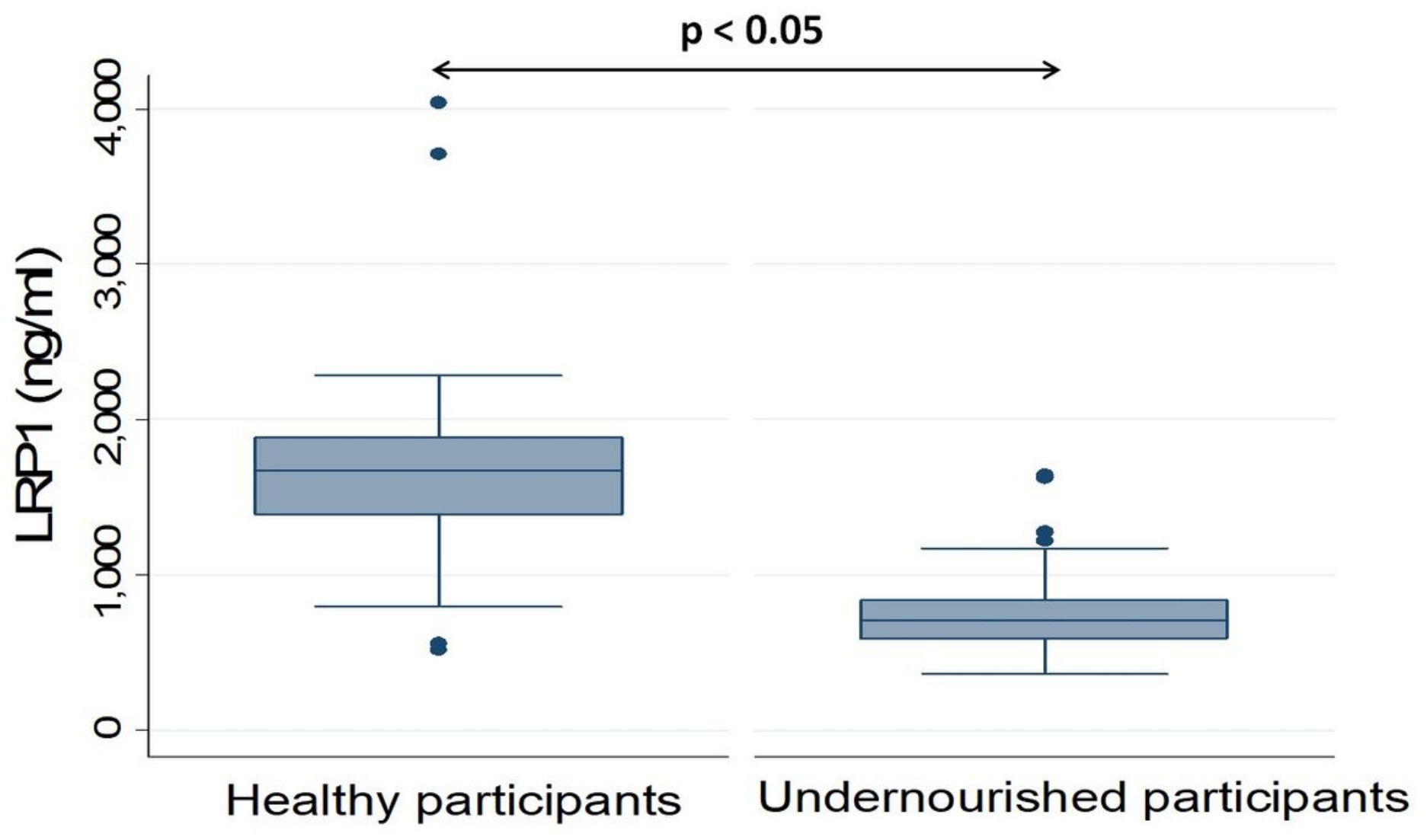

Figure 1

Comparison of Plasma LRP1 between healthy and undernourished participants 